\title{
Comunicação científica na Política Nacional de Ciência, Tecnologia e Inovação em Saúde: análise do discurso oficial
}

\section{science communication in the national Policy for Science, Technology, and Innovation in Health: analysis of the official speech}

Neide Emy Kurokawa e Silva ${ }^{a}$

(i) http://orcid.org/0000-0002-1314-8851

E-mail: neksळiesc.ufrj.br

\section{César Augusto Paro ${ }^{a}$}

(D) http://orcid.org/0000-0002-8447-9586

E-mail: cesaraugustoparoळiesc.ufrj.br

\section{Miriam Ventura ${ }^{a}$}

(D) http://orcid.org/0000-0001-8520-8844

E-mail: miriam.ventura®iesc.ufrj.br

anniversidade Federal do Rio de Janeiro. Instituto de Estudos em Saúde Coletiva. Área de Ciências Sociais e Humanas em Saúde. Rio de Janeiro, RJ, Brasil.

\section{Correspondência}

César Paro

Praça Jorge Machado Moreira, 100. Cidade Universitária, RJ, Brasil. CEP: 21941-598.

\section{Resumo}

A partir da indagação sobre as possibilidades de participação social e efetiva interação da população nas pesquisas científicas na saúde, buscou-se analisar como a Política Nacional de Ciência, Tecnologia e Inovação em Saúde aborda essa dimensão comunicativa. Deste modo, examinouse o documento oficial desta política por meio da análise temática. A comunicação sobre ciência, tecnologia e inovação à população é tratada, principalmente, no item sobre a difusão dos avanços científicos e tecnológicos, sendo designada com diferentes termos, cujos significados e objetivos, embora distintos, são tratados como sinônimos. A ideia central de comunicação gira em torno de um conteúdo a ser transferido a determinados públicos, de forma unidirecional e verticalizada, de um "emissor" para um "receptor". Tal perspectiva contrasta com a possibilidade de uma comunicação mais horizontalizada e participativa na produção de conhecimento e apropriação de tecnologias, como vislumbrado e desenvolvido por estudos e práticas sobre engajamento público na ciência ou letramento científico. Reconhecendo-se o mérito do processo que culminou nesta política e considerando o contexto político, social e cultural brasileiro é importante impulsionar propostas comunicativas de participação efetiva da sociedade nas questões de ciência, tecnologia e inovação na saúde, coerentemente com os princípios democráticos e participativos do Sistema Único de Saúde (SUS).

Palavras-chave: Ciência; Tecnologia; Saúde; Participação da Comunidade; Comunicação. 


\section{Introdução}

From the inquiry about the possibilities for social participation and effective population interaction in health research, this article aims to analyze how the communicative dimension is approached in the National Policy for Science, Technology, and Innovation in Health. For that, the official document of this policy underwent a thematic analysis. The communication of science, technology, and innovation for population features mainly at the "scientific and technological advances diffusion" section, designated under different expressions that, although presenting distinct meanings and goals, are stated as synonymous in the document. Overall, the policy considers communication as the upright and unidirectional transfer of content to specific audiences - from a sender to a receiver. Such perspective contrasts with the horizontal and participative perspective of knowledge construction and technological appropriation preconized by studies on public engagement in science and scientific literacy. Considering our political, social, and cultural context, along with the merit of the Policy's creation process, communication proposals must include an effective public participation in science, technology, and innovation in health, respecting the democratic and participative principles postulated by the National Health System.

Keywords: Science; Technology; Health; Community Participation; Communication.
A Política Nacional de Ciência, Tecnologia e Inovação em Saúde (PNCTIS) brasileira foi lançada em 2004, sendo uma extensão setorial da Política Nacional de Ciência, Tecnologia e Inovação (PNCTI), aprovada em 2001. Tendo como eixos o mérito técnico-científico e a relevância social, o seu embrião data de 1994, com a realização da I Conferência Nacional de Ciência e Tecnologia.

Foi somente após a segunda edição desta conferência em 2003 que a PNCTIS, sob a liderança do Ministério da Saúde, foi estabelecida. Em 2004 foram publicadas as suas diretrizes e a própria Agenda Nacional de Prioridades de Pesquisa em Saúde (APPMS) (Goldbaum; Serruya, 2007).

Em seu bojo, essa política propõe um conjunto de alternativas e soluções políticas para o desenvolvimento científico e tecnológico do país, considerando os interesses do Estado, do mercado e da sociedade (Brasil, 2008).

Almeida-Andrade e Carvalho (2014) relatam que, ao incluir interesses de atores tão diversos, a arena de construção da política envolveu, além das conferências, diversas instâncias de discussão, contando inclusive com uma consulta pública que embora tenha tido o modesto resultado de apenas 30\% de respostas foi compartilhada com 90 investigadores do país na área de saúde.

As mesmas autoras ressaltam também os tensionamentos do processo em relação aos interesses dos gestores de saúde para que o Ministério da Saúde liderasse o fomento à ciência, tecnologia e inovação (CTI) na saúde e o receio da comunidade científica de saúde de ser submetida a limitações que cerceariam a liberdade na produção acadêmica. Mesmo considerando a diversidade de pautas específicas, o interesse comum em defender o fomento científico e tecnológico como um setor prioritário do Sistema Único de Saúde (SUS), somado à conjuntura macropolítica favorável, permitiram a formação de uma comunidade nacional de política pública de ciência, tecnologia e inovação em saúde.

Esse breve panorama da construção da PNCTIS indica a participação de diferentes sujeitos no processo, envolvendo atores governamentais de distintos setores, bem como segmentos da sociedade 
e do complexo médico-industrial da saúde e uma ampla participação da comunidade científica.

Se essa complexa mobilização garantiu a proposição de uma política pública de CTI na saúde, a sua implementação e manutenção como tema prioritário na agenda governamental dependem do investimento contínuo na participação desses diferentes atores e consequente alocação de recursos.

No âmbito de outros setores governamentais são visíveis os retrocessos no tocante à participação social nas questões da CTI, na medida em que, em 2016, ocorreu a fusão entre os Ministérios das Comunicações (MCOM) e o da Ciência, Tecnologia e Inovação (MCTI), que resultou no Ministério da Ciência, Tecnologia, Inovações e Comunicações (MCTIC). No bojo dessa fusão, duas de suas secretarias foram integradas: a de Ciência e Tecnologia para Inclusão Social (SECIS) e a de Políticas e Programas de Pesquisas e Desenvolvimento (SEPED). O SECIS, em especial, tinha a incumbência sobre programas voltados a tecnologias apropriadas, visando ao desenvolvimento social e à difusão do conhecimento, contando com dois departamentos, o de Popularização e Difusão da Ciência e Tecnologia e o de Ações Regionais para Inclusão Social.

Entende-se que as possibilidades de participação sejam mais plausíveis e esperadas entre atores mais diretamente sensibilizados e envolvidos com o jargão da ciência e tecnologia, como os próprios cientistas e gestores, entretanto, presume-se que a atuação da sociedade, sob suas diferentes formas de representação, exigiria investimentos que propiciassem uma participação cidadã (Arnstein, 1969; Bordenave, 1983).

Para além dos aspectos éticos que envolvem a proteção dos sujeitos nos processos de produção científica, tecnológica e de inovações há também que se refletir sobre a perspectiva da ação dos indivíduos e coletividades nestes processos. Neste sentido, faz-se necessário superar as hegemônicas visões instrumental e determinista da relação de ciênciatecnologia-inovação-sociedade, mormente tratadas isoladamente, para assumir a intrínseca conexão entre estas, tal qual a partir das abordagens críticas dos Estudos de Ciência, Tecnologia e Sociedade (Estudos CTS) (Feenberg, 2015; Neder, 2013).

Compreendendo o desenvolvimento científico e tecnológico como um processo social que é conformado por dimensões culturais, políticas, econômicas e epistêmicas, os Estudos CTS têm defendido, no campo da política pública, “a regulação social da ciência e da tecnologia, provendo a criação de diversos mecanismos democráticos que facilitem a abertura de processos de tomada de decisão em questões concernentes a políticas científicotecnológicas." (Palácios et al., 2003, p. 127).

A teoria crítica da tecnologia proposta por Andrew Feenberg (2013) oferta reflexões com vistas à democratização de processos internos e ocultos que regem os códigos sociotécnicos, de modo a se privilegiar os valores excluídos para serem realizados em arranjos técnicos novos. Assumese aqui que os valores integrados às tecnologias são "socialmente incorporados", não podendo ser representados exclusivamente por categorias como eficiência e controle. Portanto, o autor propõe a centralidade da democratização da tecnologia, por meio da participação da esfera pública nas decisões sobre projeto e desenvolvimento em CTI.

Para o setor de saúde brasileiro a Constituição Federal de 1988 estabelece, dentre as competências do SUS, o incremento do desenvolvimento científico e tecnológico e a inovação em sua área de atuação (artigo 20o, inciso V) por um lado, e, ao mesmo tempo, prevê a participação da comunidade como uma das diretrizes organizativas das ações e serviços de saúde (artigo 198, inciso III), por outro. Nesse sentido, o capítulo referente ao SUS trouxe diversos desafios nas relações entre ciência-tecnologia-inovaçãosociedade para a efetivação do direito à saúde.

Este cenário de um sistema organizado a partir de uma lógica democrática traz um elemento importante para o processo de produção de conhecimento, de tecnologia e de inovação no setor saúde: a interação que a população brasileira estabelecerá com tais processos. Há, portanto, uma dimensão comunicacional na relação que ocorre entre sociedade e ciência-tecnologia-inovação em saúde, interação essa que pode ser mais ou menos bem-sucedida, a depender dos investimentos nessa dimensão.

Tais contextos nos levam a refletir sobre o modo como se prevê o conhecimento e a atuação da sociedade nas pesquisas científicas e desenvolvimento tecnológico no contexto nacional. Deste modo, nos questionamos: quais os sentidos da comunicação e 
participação social no campo da ciência e tecnologia? Como é tratada a dimensão comunicativa no âmbito da pesquisa em saúde na PNCTIS?

Considerando que, em nível programático, as políticas específicas para o setor podem ser importantes sinalizadores sobre o modo como a esfera comunicacional é incorporada, o presente artigo analisou como o documento oficial da PNCTIS aborda essa dimensão comunicativa.

Antes de abordar o percurso desta investigação, cabem algumas notas sobre os principais conceitos que tratam da participação social ou da comunicação na relação entre ciência, tecnologia e sociedade, uma vez que os estudos a respeito se utilizam de diferentes terminologias, que expressam diferentes significados.

\section{Comunicação, ciência e tecnologia}

Uma mirada na literatura sobre comunicação no âmbito da ciência e tecnologia nos oferece um vasto campo de conceitos e terminologias, sendo interessante notar variações nos significados para um mesmo termo.

Dentre os termos mais comuns, angariados na literatura nacional, destacam-se o de divulgação, difusão, comunicação, alfabetização, letramento, vulgarização e popularização da ciência. Outra variação terminológica, menos comum no Brasil, diz respeito ao engajamento científico.

O Descritores em Ciências da Saúde (DeCS) ${ }^{1}$ utiliza o termo "comunicação e divulgação científica", que distingue a comunicação da divulgação, por referência aos públicos aos quais se dirige:

Comunicação, publicação e disseminação de resultados de pesquisa científica em artigos, livros e outros documentos bibliográficos, os quais podem ser pagos ou grátis, impressos ou virtuais e, geralmente, revisados por pares. A comunicação científica pode ser direcionada a cientistas e acadêmicos ou ao público em geral, sendo, neste caso, chamada de "divulgação científica".

Nessa perspectiva, além da comunicação voltada para outros cientistas e para a própria ciência, na divulgação científica, destinada a não-cientistas, identificam-se basicamente três vertentes: o ensino de ciência, no espaço escolar, que teria como mote incentivar a formação de novos cientistas; a descodificação dos achados científicos para o público em geral, via notícias veiculadas nas diferentes mídias; a comunicação com vistas a profissionais, técnicos, gestores, potencialmente consumidores das descobertas, como é o caso de achados na área de medicamentos.

Outra maneira de diferenciar os termos referese ao momento que ocorre a comunicação, como o da divulgação da pesquisa ou de seu produto tecnológico, e até mesmo no desenho do estudo e na agenda de pesquisas.

Além dos veículos, públicos e momentos de divulgação/interação envolvidos na comunicação científica é possível discernir modelos comunicacionais que informam os significados e práticas em torno dessa comunicação.

Entende-se aqui por modelo as características comuns acerca dos horizontes éticos, políticos e epistemológicos que o orientam. Isto é, ao apostar que a comunicação a um público leigo, por exemplo, se subsome à transmissão de informações, assumese, ainda que indiretamente, determinada visão em relação a esse público, como o fato de que não possui conhecimentos válidos - prerrogativa da ciência e dos cientistas -, e que esse déficit deve ser suprido com as informações. Ainda nesse exemplo, o momento de inclusão do público no processo também diz muito sobre os horizontes que guiam a comunicação, seja na concepção do que é relevante socialmente, seja apenas na informação sobre resultados de pesquisas.

Essa perspectiva é bastante explorada na literatura que discrimina a alfabetização do letramento científico, radicadas a partir da tradição dos estudos em scientific literacy, dos Estados Unidos. Em que pesem os deslizes em relação à sua tradução e apropriação, a alfabetização focalizaria a capacidade técnica de ensino/aprendizagem da leitura e escrita, enquanto o letramento se preocuparia com a capacidade da leitura e escrita em propiciar práticas que operem transformações nas 
condições sociais, ou seja, possibilitem "reescrever" a realidade (Cunha, 2014).

Já na herança espanhola, a expressão alfabetización científica designa “o ensino cujo objetivo seria a promoção de capacidades e competências entre os estudantes capazes de permitir-lhes a participação nos processos do dia-a-dia" (Sasseron; Carvalho, 2011, p. 6o).

Ainda sobre a noção de alfabetização científica, Germano e Kulesza (2007, p. 13) resgatam a diferenciação entre alfabetização científica prática, cívica e cultural:

A alfabetização científica prática é aquela que contribui para a superação de problemas concretos, tornando o indivíduo apto a resolver, de forma imediata, dificuldades básicas que afetam a sua vida. A alfabetização científica cívica seria a que torna o cidadão mais atento para a Ciência e seus problemas, de modo que ele e seus representantes possam tomar decisões mais bem informadas. Num outro nível de elaboração cognitiva e intelectual, estaria a alfabetização científica cultural procurada pela pequena fração da população que deseja saber sobre Ciência, como uma façanha da humanidade e de forma mais aprofundada.

Para a mesma expressão, são propostos diferentes objetivos e públicos, reforçando a pluralidade de sentidos contida em uma mesma palavra ou termo, podendo abrigar significados e práticas bastante díspares.

Um jargão menos conhecido no Brasil, proveniente da comunicação pública de ciência e que também abriga diferentes acepções é o engajamento público na ciência ${ }^{2}$, utilizado nas análises sobre relações entre cidadãos com a ciência e tecnologia.

O engajamento público na ciência, a exemplo do letramento científico, transcende a mera difusão do conhecimento, enquanto transmissão de informações ao público, postulando-se uma efetiva apropriação por parte do mesmo e a integração com outros saberes, a serem utilizados em tomadas de decisão:

Envolve o compromisso entre sociedade e ciência, através do diálogo, em particular através de uma discussão aberta e de igual para igual que possibilite aos leigos tornarem-se os protagonistas nas decisões científicas com impacto social... Esta posição mais igualitária de envolvimento público, como parte fundamental de uma democracia forte e consolidada, estabelece uma via de duplo sentido: o conhecimento público da ciência e o conhecimento da comunidade científica sobre o público (Oliveira; Carvalho, 2015, p. 156).

O breve panorama traçado, ao indicar a pluralidade de designações para a comunicação no âmbito da ciência e tecnologia (CT) e o gradiente entre focos, modelos comunicacionais e públicos envolvidos abriga desde abordagens mais verticalizadas, baseadas na noção de déficit de conhecimento do público leigo, que precisaria de informações sobre as descobertas científicas, a fim de poder consumir as novas tecnologias, até aquelas mais horizontalizadas, em que a participação dos cidadãos não se reduz a informação sobre o resultado do estudo, mas prevê o seu protagonismo, inclusive na definição das prioridades sociais.

À guisa de uma síntese dos modelos de comunicação na ciência é possível delinear uma síntese acerca das principais características de cada um deles, lembrando-se que os termos podem assumir outros significados, a depender dos autores que os abordam (Quadro 1). 
Quadro I - Designações e principais características da comunicação na ciência

\begin{tabular}{|c|c|c|c|}
\hline DESIGNAÇÃO & FOCO & MODELO COMUNICACIONAL & PÚBLICO \\
\hline $\begin{array}{l}\text { Comunicação } \\
\text { científıca }\end{array}$ & $\begin{array}{l}\text { Conhecimento científico e população } \\
\text { (cientistas e não cientistas); troca de } \\
\text { conhecimentos científicos }\end{array}$ & $\begin{array}{l}\text { Horizontalizado; cientistas } \\
\text { para cientistas }\end{array}$ & Pares \\
\hline $\begin{array}{l}\text { Difusão } \\
\text { cientifica }\end{array}$ & $\begin{array}{l}\text { Informacional; transmissão de } \\
\text { conhecimentos científicos }\end{array}$ & $\begin{array}{l}\text { Verticalizado; cientistas } \\
\text { (que têm conhecimento) } \\
\text { para população (sem } \\
\text { conhecimento) }\end{array}$ & $\begin{array}{l}\text { Consumidores de } \\
\text { tecnologias e usuários de } \\
\text { informações científicas }\end{array}$ \\
\hline $\begin{array}{l}\text { Divulgação } \\
\text { científıca }\end{array}$ & $\begin{array}{l}\text { Informacional; transmissão de } \\
\text { conhecimentos científicos }\end{array}$ & $\begin{array}{l}\text { Verticalizado; cientistas } \\
\text { (que têm conhecimento) } \\
\text { para população (sem } \\
\text { conhecimento) }\end{array}$ & $\begin{array}{l}\text { Consumidores de } \\
\text { tecnologias e usuários de } \\
\text { informações científicas }\end{array}$ \\
\hline $\begin{array}{l}\text { Alfabetização } \\
\text { científıca }\end{array}$ & $\begin{array}{l}\text { Pedagógico; informacional; melhoria } \\
\text { do ensino de ciências; fomento de } \\
\text { cultura de pesquisa }\end{array}$ & $\begin{array}{l}\text { Verticalizado; cientistas (que } \\
\text { têm conhecimento) para } \\
\text { estudantes e/ou população } \\
\text { (sem conhecimento) }\end{array}$ & Estudantes; população \\
\hline $\begin{array}{l}\text { Vulgarização } \\
\text { da ciência }\end{array}$ & $\begin{array}{l}\text { Informacional; tradução de linguagem } \\
\text { especializada em linguagem comum }\end{array}$ & $\begin{array}{l}\text { Verticalizado; cientistas } \\
\text { (que têm conhecimento) } \\
\text { para população } \\
\text { (sem conhecimento) }\end{array}$ & $\begin{array}{l}\text { Consumidores de } \\
\text { tecnologias e usuários de } \\
\text { informações científicas }\end{array}$ \\
\hline $\begin{array}{l}\text { Popularização } \\
\text { da ciência }\end{array}$ & $\begin{array}{l}\text { Informacional; pedagógico; tradução } \\
\text { de linguagem especializada em } \\
\text { linguagem comum }\end{array}$ & $\begin{array}{l}\text { Verticalizado } \\
\text { (podendo ter nuances } \\
\text { de compartilhamento) }\end{array}$ & $\begin{array}{l}\text { Consumidores de } \\
\text { tecnologias e usuários de } \\
\text { informações científicas }\end{array}$ \\
\hline $\begin{array}{l}\text { Letramento } \\
\text { cientifico }\end{array}$ & $\begin{array}{l}\text { Democratização da CTI; pedagógico; } \\
\text { político; possibilidade de compreensão } \\
\text { crítica da CTI pelo público leigo }\end{array}$ & $\begin{array}{l}\text { Horizontalizado; definição } \\
\text { conjunta da agenda científica }\end{array}$ & Cidadãos \\
\hline $\begin{array}{l}\text { Engajamento } \\
\text { público }\end{array}$ & $\begin{array}{l}\text { Democratização da CTI; participação; } \\
\text { político; possibilidade de compreensão } \\
\text { crítica da CTI pelo público leigo }\end{array}$ & $\begin{array}{l}\text { Horizontalizado; definição } \\
\text { conjunta da agenda científica }\end{array}$ & Cidadãos \\
\hline
\end{tabular}

\section{Percurso da pesquisa}

Tratou-se de uma pesquisa exploratória de abordagem qualitativa que analisou como a PNCTIS aborda a comunicação científica a partir de análise documental, fundada no entendimento de que o documento pode auxiliar na compreensão das realidades sociais em contextos institucionais (Flick, 2009).

Selecionou-se a segunda edição da PNCTIS (Brasil, 2008) por ser a publicação atualmente vigente. A primeira edição havia sido publicada em 2005, a partir da sua aprovação na II Conferência Nacional de Ciência, Tecnologia e Inovação em Saúde e na $147^{\text {a }}$ Reunião Ordinária do Conselho Nacional de Saúde, ambas realizadas em 2004.

O exame do documento selecionado levou em conta o binômio conteúdo/contexto de produção, considerando que trata-se de um "dispositivo comunicativo" que é resultado de um processo histórico, social e político específico e não um "contêiner de informações" (Flick, 2009).

A análise do material recorreu às proposições da Bardin (2016) acerca da análise temática. A leitura do documento foi guiada tanto pelo contexto de construção da PNCTIS quanto pelo levantamento da terminologia utilizada para tratar do tema. Selecionou-se as informações pertinentes aos processos 
comunicacionais, para, posteriormente, proceder com a exploração do material por meio da operação de codificação, com o recorte dos dados e sua compilação em unidades de significados (temas e subtemas), para, enfim, os dados serem descritos e interpretados.

Nesta fase interpretativa, buscou-se realizar o diálogo dos achados a partir dos referenciais teórico-conceituais de críticos da Saúde Coletiva e dos Estudos CTS.

\section{Resultados e discussão}

\section{A "população" na PNCTIS}

A filiação da PNCTIS é demarcada no início do documento, apontando como balizadores os princípios da Política Nacional de Saúde (PNS) no âmbito do SUS e da PNCTI.

Na sua relação com a PNS, destaca a consonância com os princípios constitucionais da universalidade, integralidade e equidade, gerando o compromisso ético e político com "a produção e com a apropriação de conhecimentos e tecnologias que contribuam para a redução das desigualdades sociais em saúde, em consonância com o controle social" (Brasil, 2008, p. 5). Em relação à PNCTI, registra os princípios do mérito técnico-científico e relevância social, salientando que a produção de conhecimentos técnicos e científicos seja ajustada às necessidades econômicas, sociais, culturais e políticas do país, objetivando o desenvolvimento nacional, de modo sustentável.

A menção à relevância social é retomada no documento como um dos eixos condutores da PNCTIS, conjugada à relevância sanitária e econômica. As principais ideias associadas ao termo "relevância social, sanitária e econômica”, no documento, dizem respeito ao avanço do conhecimento - sugerindo a competitividade e o desenvolvimento - e à utilidade dos conhecimentos produzidos, visando à solução de problemas prioritários para a saúde (Brasil, 2008).

Mesmo levando em conta as possíveis tensões entre o princípio da equidade, emanado do SUS, visando reduzir as desigualdades sociais em saúde, e os princípios de relevância social e econômica, preceituado pela PNCTI, o documento reflete a coexistência entre uma tônica econômica e desenvolvimentista, característica de uma política de ciência e tecnologia, e a do compromisso com os preceitos democráticos e participativos constitucionais.

Apesar do documento demonstrar com clareza o papel dos atores das instituições de pesquisa e do Ministério da Saúde na formulação da PNCTIS não é evidente a atuação da sociedade em geral, ora mencionada como representantes de movimentos sociais, ora como controle social, sendo apenas registradas suas presenças nas conferências que precederam a formulação da política (Andrade; Camargo, 2014; Goldbaum; Serruya, 2007).

Deduz-se a complexidade de um processo envolvendo atores com interesses, conhecimentos, poderes e capacidades argumentativas tão diversas e, no caso da população, para quem o tema não faz parte do cotidiano, a sua participação no debate pode ser comprometida.

O questionamento acerca da qualidade da participação da população na construção da PNCTIS situa-se na indagação mais ampla sobre sua relação com a CTI.

\section{Comunicação científica na PNCTIS}

A difusão científica é justificada no decorrer do texto da PNCTIS a partir das insuficiências na introdução de formas de comunicação acessíveis e compreensíveis para o público leigo e para profissionais de saúde, que teriam como consequências a baixa utilização do conhecimento científico e barreiras à participação social.

O principal ponto de convergência sobre comunicação entre CTI e a sociedade na política se dá a partir da noção de difusão do conhecimento e de termos correlatos.

O uso desses termos concentra-se basicamente: a) no capítulo referente à situação atual da ciência e da tecnologia no Brasil, no item sobre formação de recursos humanos; b) no capítulo sobre estratégias da PNCTIS, no item específico sobre Difusão dos Avanços Científicos e Tecnológicos.

Da análise textual as palavras que mais figuraram no documento, relacionadas à comunicação, foram: “divulgação", com nove ocorrências e "difusão", com sete ocorrências. Na sequência, "comunicação" foi reportada cinco vezes e "disseminação" e “popularização”, quatro e duas vezes, respectivamente. 
Observam-se deslizamentos semânticos entre as palavras ou termos alusivos à comunicação científica, tratando-os como sinônimos, embora a divulgação científica, via de regra, tenha se referido à comunicação para público de não cientistas, como consta da noção presente nos DeCs.

Vale lembrar que a etimologia das palavras divulgação, difusão, disseminação e popularização radica do latim, significando "espalhar" (Houaiss; Villar, 2001). Já a comunicação, pode apresentar dois sentidos, conforme postulam Germano e Kulesza (2007, p. 15):

Proveniente de uma palavra latina: communis, que significa "por em comum", a comunicação pode apresentar dois sentidos. 0 primeiro transitivo "comunicar", equivalente a informar e transmitir e o segundo de comunicar-se, em diálogo horizontal com o outro. No sentido transitivo, a comunicação estaria intimamente aproximada com divulgação, e haveria que se supor que comunicar seria transmitir ao vulgo (di-vulgare), algo que um ator ou um setor social especializado possui e tem construído.

No documento, pode-se destacar uma ideia central em torno da noção de comunicação, que se alinharia ao primeiro sentido transitivo de informar, ou seja, o de um conteúdo (conhecimento) a ser transferido a determinados públicos, tomando a comunicação de maneira unidirecional, de um "emissor" para um "receptor".

Esse é o modelo tradicional nas práticas comunicativas, reproduzido, hegemonicamente, na área de saúde. Parte do pressuposto de um "emissor" que detém o conhecimento científico (profissionais de saúde) e o transmite a um "receptor" sem conhecimento científico (usuários dos serviços). No caso, o conhecimento leigo desses últimos, ou são simplesmente desconsiderados ou tomados como obstáculos à compreensão do único conhecimento válido, o oriundo da ciência (Becker, 2008; Teixeira, 1997). Trata-se de uma relação entre sujeitos e objetos, típicos do que Paulo Freire (2016) denominou educação bancária, a qual, para além dos aspectos epistemológicos, denuncia os valores, ideologias, desigualdades e poderes subjacentes, resultando em um modelo transmissional e verticalizado de comunicação, que pode ser equiparado ao modelo top-down de comunicação científica (Bensaude Vincent, 2014).

Deduz-se o predomínio desse tipo de relação no modo como a comunicação entre CTI e o público de não cientistas é tratado no documento da PNCTIS a partir de frases que sugerem tal relação:

[...] favorecer a divulgação das informações científicas para a sociedade (Brasil, 2008, p. 33, grifo nosso).

[...] apoiar e ampliar as iniciativas que favoreçam a divulgação científica para pesquisadores, empresários, gestores, profissionais de saúde, estudantes dos diversos níveis, etapas e modalidades da educação brasileira, com ênfase nos cursos da área de saúde, e para a sociedade civil (Brasil, 2008, p. 31, grifo nosso).

[...] formas de comunicação acessíveis e compreensíveis para o público leigo e para profissionais de saúde (Brasil, 2008, p. 10, grifo nosso).

O uso da preposição "para” reforça o forte sentido transmissional das palavras difusão e divulgação, bastante presentes no documento. Coerentemente, a difusão dos avanços científicos e tecnológicos é o termo escolhido para designar uma das estratégias da PNCTIS.

O público "receptor" da divulgação é identificado na PNCTIS como: público leigo; profissionais de saúde; pesquisadores; empresários; gestores e trabalhadores da saúde e da educação, federais, estaduais e municipais e dos conselhos; sociedade civil organizada; controle social; profissionais de saúde; e estudantes de diversos níveis, etapas e modalidades da educação brasileira com ênfase em cursos da saúde.

0 termo popularização da ciência reduz-se à sua menção como estratégia para difusão da ciência, a partir da criação de núcleos e fóruns, e à participação do setor saúde na Semana de Popularização da Ciência e Tecnologia no Brasil, sobre a qual não se encontrou referências na literatura.

Germano e Kulesza (2007) lembram a diferença entre popularização e vulgarização, mesmo considerando o trânsito semântico entre ambas: 
[...] popularizar é muito mais do que vulgarizar ou divulgar a ciência. É colocá-la no campo da participação popular e sob o crivo do diálogo com os movimentos sociais. É convertê-la ao serviço e às causas das maiorias e minorias oprimidas numa ação cultural que, referenciada na dimensão reflexiva da comunicação e no diálogo entre diferentes, oriente suas ações respeitando a vida cotidiana e o universo simbólico do outro. Portanto, diferentemente de sua concepção inglesa, acreditamos que o termo popularização da ciência tenha ganhado força na América Latina, por conta das diversas lutas populares que marcam a história da região. Em um cenário no qual vimos nascer uma Teologia da Libertação, uma Pedagogia do Oprimido e uma Educação Popular, é natural que o termo tenha uma presença marcante (p. 20, grifo nosso).

As considerações do autor levam a esperar que a PNCTIS pudesse explorar de modo mais consistente os significados que o termo popularização tem na América Latina e no Brasil, em consonância com as referências citadas.

Dentre as finalidades enunciadas para as iniciativas de divulgação, pode-se distinguir um conjunto de termos e palavras vinculadas basicamente a dois polos de significado: um voltado para a ideia de promoção da cidadania na interface com a CTI e outro mais identificado com a noção de CTI enquanto mero objeto de consumo:

- Promoção da cidadania: Equidade, participação social e socialização da produção científica e tecnológica.

- Consumo de CTI: Utilização do conhecimento produzido; apropriação social ampla dos benefícios da ciência, da tecnologia e da inovação em saúde; difusão do progresso técnico; e o apoio à inovação, divulgação de conhecimentos técnicos e científicos, de forma acessível para a sociedade.

O contraponto entre participação cidadã e consumo de conhecimento e tecnologia corresponderia, respectivamente, na distinção entre letramento científico, engajamento público na ciência e popularização da ciência, por um lado, e alfabetização, difusão e divulgação científica, por outro.
Os espaços e meios de comunicação arrolados no texto da PNCTIS reforçam a ênfase na ideia de difusão, já que se circunscrevem majoritariamente ao acesso a bibliotecas, revistas, internet, museus, centros de ciências e centros de integração ciência e cultura. A alusão ao estímulo a fóruns de debate se ateve na finalidade de divulgar resultados de pesquisa que envolvam riscos à saúde.

Em uma única oportunidade, ao abordar a criação do Sistema Nacional de Inovação em Saúde, o documento trouxe à tona a possibilidade de participação da população (ainda que determinado segmento desta) em etapa anterior à própria produção científica e tecnológica, não restrita à recepção de informações/conhecimentos:

Os conselhos de saúde e demais instâncias de controle social e de gestão de CTI/S [Ciência, Tecnologia e Inovação em Saúde], nas três esferas de governo, devem incentivar e promover discussões sobre as demandas em tecnologia nesse campo, visando a melhorias dos serviços de saúde e garantia de acesso às novas tecnologias (Brasil, 2008, p. 23).

O tom crítico ao modelo comunicacional que marca a PNCTI, em que pesem os limites de uma política, emerge da expectativa de que o documento tivesse abertura mais explícita a espaços de formação e discussão, em uma aproximação mais compartilhada entre CTI e população.

\section{Considerações finais}

Ao lado do reconhecimento do mérito e do processo democrático que culminou na PNCTIS, que reflete as possibilidades da realidade brasileira, não se furta ao ímpeto de cotejá-la com propostas mais ambiciosas que tomam a comunicação em seu sentido mais amplo, de participação efetiva da sociedade nas questões de CTI e saúde. É como se estivéssemos "desperdiçando" o amparo de nossa Constituição cidadã no que tange ao protagonismo dos sujeitos, sejam cientistas, técnicos ou a população geral.

É certo que a perspectiva dialógica defendida a partir de uma concepção reflexiva de comunicação não é isenta de conflitos, posto que, em geral, trata-se 
de uma interação envolvendo diferentes atores, diferentes interesses.

Em meio à profusão de termos que aspiram expressar ambição de uma interação mais democrática e participativa entre CTI e população, parece que o de letramento científico e o de engajamento público na ciência coadunam-se com a proposta.

Para discorrer sobre letramento é inevitável não confrontá-lo com o de alfabetização científica. A alfabetização se restringiria ao ato de ensinar a ler e escrever, ao passo que o letramento expressaria mais do que isso, pois incorpora o cultivo e o exercício de práticas sociais que usam a escrita (Soares, 1988), ou seja, se relacionaria com o uso social do conhecimento científico.

Na mesma linha, o engajamento público na ciência diz respeito a uma interação e integração entre públicos especialistas e não especialistas na discussão de temas científicos-tecnológicos, a partir da aposta em aprendizagens recíprocas e resoluções de problemas nesse campo.

Diante de uma política de CTI que enfatiza a difusão de resultados de pesquisas, a fim de cientificar a população sobre as mesmas ou então para legitimá-las, quais os investimentos na formação de cidadãos que de fato possam interagir e se engajar com a CTI? Quais as aberturas para efetivo diálogo entre atores e entre conhecimentos científicos e populares? Enfim, quanto temos a capacidade e vontade de "estranhar" a noção transmissional e verticalizada de comunicação?

\section{Referências}

ARNSTEIN, S. R. A ladder of citizen participation. Journal of the American Institute of Planners, Abingdon, v. 35, n. 4, p. 216-224, 1969. DOI: 10.1080/01944366908977225

ALMEIDA-ANDRADE, P.; CARVALHO, D. B. B. D. Formulação da política nacional de ciência, tecnologia e inovação em saúde: retrospectiva do movimento dos grupos de interesse. Revista de Políticas Públicas, São Luís, v. 18, n. 2, p. 573-585, 2014. DOI: 10.18764/2178-2865.v18n2p573-585

BARDIN, L. Análise de conteúdo. Lisboa: Edições 70, 2016.
BECKER, F. Modelos pedagógicos e modelos epistemológicos. In: ALVES, E. L. et al. (Org.). Metodologia. Construção de uma proposta científica. Curitiba: Editora Camões, 2008.

BENSAUDE VINCENT, B. The Politics of Buzzwords at the Interface of Technoscience, Market and Society: The Case of 'Public Engagement in Science'. Public Understanding of Science, Thousand Oaks, v. 23, n. 3, p. 238-253, 2014. DOI: 10.1177/og63662513515371

BORDENAVE, J. E. D. O que é participação.

São Paulo: Brasiliense, 1983.

BRASIL. [Constituição (1988)]. Constituição da República Federativa do Brasil de 1988. Brasília, DF: Senado Federal, 2021.

BRASIL. Ministério da Saúde. Secretaria de Ciência, Tecnologia e Insumos Estratégicos. Departamento de Ciência e Tecnologia. Política nacional de ciência, tecnologia e inovação em saúde. 2. ed. Brasília, DF, 2008.

CUNHA, R. B. Alfabetização científica ou letramento científico?: interesses envolvidos nas interpretações da noção de scientific literacy. Revista Brasileira de Educação, Rio de Janeiro, v. 2, n. 68, p. 169-186, 2014. DOI: 10.1590/S141324782017226809

FEENBERG, A. Tecnologia, modernidade e democracia. Organização e tradução de Eduardo Beira. Lisboa: IN+ Center for Innovation, Technology and Public Policy, 2015.

FEENBERG, A. Teoria crítica da tecnologia: um panorama. In: NEDER, R. T. (Org.). A teoria crítica de Andrew Feenberg: racionalização democrática, poder e tecnologia. 2. ed. Brasília, DF: Observatório do Movimento pela Tecnologia Social na América Latina/CDS/UnB/Capes, 2013. p. 97-117.

FLICK, U. Introdução à pesquisa qualitativa. Tradução de Joice Elias Costa. 3. ed. Porto Alegre: Artmed, 2009.

FREIRE, P. Pedagogia do Oprimido. 62. ed. Rio de Janeiro: Paz e Terra, 2016.

GERMANO, M. G; KULESZA, W. A. Popularização da ciência: uma revisão conceitual. Caderno Brasileiro 
de Ensino de Física, Florianópolis, v. 24, n. 1, p. 7-25, 2007. DOI: https://doi.org/10.5007/\%25x

GOLDBAUM, M.; SERRUYA, S. O Ministério da Saúde na política de ciência, tecnologia e inovação em saúde. Revista USP, São Paulo, n. 73, p. 40-47, 2007. DOI: 10.116o6/issn.2316-9o36.voi73p4o-47

HOUAISS, A.; VILLAR, M. de S. Minidicionário Houaiss da Língua Portuguesa. Rio de Janeiro: Objetiva, 2001.

NEDER, R. T. (Org.). A teoria crítica de Andrew Feenberg: racionalização democrática, poder e tecnologia. 2. ed. Brasília, DF: Observatório do Movimento pela Tecnologia Social na América Latina/CDS/UnB/Capes, 2013.

OLIVEIRA, L. T. de; CARVALHO, A. Public engagement with science and technology: contributos para a definição do conceito e a análise da sua aplicação no contexto português. Observatorio (OBS*) Journal, Braga, v. 9, n. 3, p. 155-178, 2015. DOI: 10.15847/obsOBS932015857

PALÁCIOS et al. (Org.). Introdução aos Estudos CTS:(Ciência, Tecnologia e Sociedade). Brasília, DF: Organização dos Estados Ibero-Americanos para Educação, Ciência e Cultura, 2003.

SASSERON, L. H.; CARVALHO, A. M. P. de. Alfabetização científica: uma revisão bibliográfica. Investigações em Ensino de Ciências, Porto Alegre, v. 16, n. 1, p. 59-77, 2011.

SOARES, M. Letramento: um tema em três gêneros. Belo Horizonte: Autêntica, 1998.

TEIXEIRA, R. R. Modelos comunicacionais e práticas de saúde. Interface - Comunicação, Saúde, Educação, Botucatu, v. 1, n. 1, p. 7-40, 1997. DOI: 10.1590/S1414-32831997000200002

\section{Agradecimentos}

Agradecemos as contribuições críticas de Kenneth Rochel de Camargo Jr. em relação a estruturação do texto.

\section{Contribuição dos autores}

Os pesquisadores participaram de todas as etapas da pesquisa $e$ redação do manuscrito.

Recebido: 20/06/2019

Aprovado: 31/05/2021 